\title{
Multivariate Statistical Analysis of the UV-Vis Profiles of Wine Polyphenolic Extracts during Vinification
}

\author{
Roberta Sanna ${ }^{1}$, Cristina Piras ${ }^{1}$, Flaminia Cesare Marincola ${ }^{1}$, Valentina Lecca ${ }^{1}$, Sergio Maurichi ${ }^{2} \&$ Paola Scano ${ }^{1}$ \\ ${ }^{1}$ Department of Chemical and Geological Sciences, University of Cagliari, Cittadella Universitaria di \\ Monserrato, SS554 bivio per Sestu, Monserrato (CA), Italy \\ ${ }^{2}$ Azienda Agraria Duca degli Abruzzi, Via Acquedotto Romano, Zona Industriale Est, Elmas (CA), Italy \\ Correspondence: Roberta Sanna, PhD Department of Chemical and Geological Sciences, University of Cagliari, \\ Cittadella Universitaria di Monserrato, SS 554 bivio per Sestu, 09042, Monserrato (CA), Italy. Tel: \\ 39-070-675-4392. Fax: 39-070-675-4388. E-mail: roberta.sanna@hotmail.it
}

Received: July 23, 2014 Accepted: September 18, 2014 Online Published: November 15, 2014

doi:10.5539/jas.v6n12p152 URL: http://dx.doi.org/10.5539/jas.v6n12p152

\begin{abstract}
Multivariate Statistical data Analysis (MVA) was used to study the changes undergone by the UV-Vis spectral profiles of polyphenolic components during vinification. Two Sardinian wines, from the white cultivar "Vermentino" and from the red "Cannonau", were studied. The wine samples were collected at different times from the fermentation vessels and the UV-Vis spectra of their solid phase extracts (SPE) were submitted to PCA (Principal Component Analysis) and to Orthogonal Projections to Latent Structures (OPLS) regression analysis in order to look for the main source of variability present in the spectra in terms of grape typology and winemaking times. In Vermentino, during the first weeks of vinification the prevalent modifications regarded the increase of the bands at 280 and $350 \mathrm{~nm}$, attributed to HBA, stilbenes flavan-3-ols and glycosylated flavonols, respectively; at approximately 60 days a bathocromic shift of the band at $350 \mathrm{~nm}$ towards $380 \mathrm{~nm}$ took place, suggesting hydrolysis of flavonols. In Cannonau, the band at $536 \mathrm{~nm}$, attributed to anthocyanins, that showed a consistent increase in the first days of vinification, after 11 days dropped significantly, exhibiting also a bathochromic shift. The band at $380 \mathrm{~nm}$ was linearly positively correlated with time. Our results support the potential use of this approach for qualitatively monitoring the winemaking process.
\end{abstract}

Keywords: OPLS, PCA, SPE extracts, UV-Vis spectroscopy, wine polyphenols

\section{Introduction}

Winemaking, from grapes to the final product, is a laborious process that involves continuous transformations of the chemical compounds present in the starting raw material: the grapes. The chemistry of winemaking is a complex topic where the sugar contained in the grape juice is mainly converted into ethanol and a plethora of other minor compounds. Other minor classes of chemical compounds are subject to transformation. Among these, polyphenols, even if present in very low concentration, can greatly affect the sensorial and organoleptic characteristics and stability of wine (Lubbers \& Voilley, 1997). Besides, this typology of compounds is nowadays regarded with growing interest for the reported evidence of their beneficial health effects, among which their antimicrobial, antiviral and anti-inflammatory properties along with their high antioxidant capacity (Tuberoso, Boban, Bifulco, Budimir, \& Pirisi, 2013). Polyphenols encompass a wide range of chemical compounds, having in common a benzenic ring with one or more hydroxyl groups directly attached. Wine and wine grape polyphenols can be classified as: i) flavonoids, including flavan-3-ols (cathechins and condensed tannins), flavonols, and anthocyanins; and ii) non-flavonoids, including phenolic acids, (hydroxycinnamates, hydroxybenzoates (HBA), hydrolysable tannins) and stilbenes (mainly trans-resveratrol) (Pinelo, Laurie, \&Waterhouse, 2006). In red wines, the concentration of polyphenols, principally flavonoids, generally is ten times higher than that of white wines, these latter being characterized mainly by non-flavonoids. Due to these differences, the red wines show a heightened antioxidant capacity than the white wines (Rice-Evans, Miller, \& Paganga, 1997). The final phenolic content of wine is strongly influenced by the winemaking processes such as duration of maceration step, temperature and stirring of fermentative medium (Gao, Girard, Mazza, \& Reynolds, 1997). Mainly two processes determine the changes in the phenolic composition: the first one involves enzymatic reactions and occurs mostly at the early stages of winemaking, while, in the second one, the chemical 
reactivity of the phenolic compounds plays an important role, beginning in the winemaking process and continues during aging (Cheynier, Moutounet \& Sanri-Manchado, 2000; Cheynier \& Ricardo Da Silva, 1991; Sarni-Manchado, Cheynier, \& Moutounet, 1997). During both phases, polyphenols are involved in several chemical reactions influencing the color, the color stability, the body and the astringency of the wine (Gonzáles-Manzano, Dueñas, Rivas-Gonzalo, Escribano-Bailón, \& Santos-Buelga, 2009; Vidal et al., 2003; Vidal et al., 2004; Fontoin, Saucier, Teissedre, \& Glories, 2008). Given that the polyphenolic fraction is present in wines in very low concentration, the solid phase extraction (SPE) over C18 columns has been proved to be a powerful tool for the isolation, purification and concentration of these molecular compounds from the wine matrix prior the analytical investigation (Briviba, Pan, \& Rechkemmer, 2002; Edelmann, Diewok, Schuster, \& Lendl, 2001). Among analytical techniques, UV-Vis spectroscopy is well suited for the study of polyphenol compounds because they are $\pi$ conjugated systems, containing OH-phenolic groups. The UV-Vis spectrum of these molecular components is attributed to electronic transitions between $\pi$ type molecular orbitals, the extension of which over the molecular backbone depends on the different sub-classes of polyphenols (Anouar, Gierschner, Duoux, \& Trouillas, 2012). In wine research, this spectroscopic technique has mainly been applied to the identification of anthocyanins, flavonoids and non-flavonoids and to the measurement of their concentrations (Anouar et al., 2012). A different application consists in collecting the whole spectrum (within a determined range) allowing to monitor, in samples undergoing different conditions, the behavior of known and unknown molecular components that absorb in the selected nm range (Cozzolino, Parker, Dambergs, Herderich, \& Gishen, 2006). Due to the huge amount of data provided by this untargeted approach and when spectra, collected for a number of samples, have to be compared, to unrevealing the information in them contained, a MVA is suggested. This combined approach has been widely applied in the study of complex biological matrices, among which grape and wine (Azcarate, Cantarelli, Pellerano, Markevsky, \& Camina, 2013; Urbano, Luque de Castro, P'erez, Garc'ia-Olmo, \& Gomez, 2006; Garcì-Jares, 1993, Cozzolino, Cynkar, Shah, Dambergs, \& Smith, 2009, Saurina, 2010, Gishen, Dambergs, \& Cozzolino, 2005).

In this work, two wines produced from Cannonau and Vermentino, the most typical and widespread cultivars of the island of Sardinia (Italy) were studied. Cannonau gives a red wine and Vermentino a white one. As reported in the literature, the total mean contents of polyphenols in Vermentino and Cannonau wines are around 130 and 1700 (expressed as mg/L of (+) catechin), respectively (Sanna, Ledda, Manca, \& Franco, 2008). Interestingly, the high content of flavonoids in red wine obtained from the Cannonau variety through traditional manufacture, has been correlated to the longevity of people living in Nuoro province (Sardinia, Italy) regularly consuming moderate doses of this wine (Corder, Mullen, Khan, Wood, Carrier, \& Crozier 2006).

The aim of this study was to investigate the potential of different MVA techniques applied to UV-Vis spectral data for monitoring the evolution of the polyphenolic components of these wines during vinification. To this goal, full spectra, in the range 240-650 nm, of the SPE extracts were acquired and the spectral data submitted to PCA and OPLS regression. This work will be focusing mainly on the interpretation of spectral modifications and of PCA and OPLS results, rather than developing calibration models to monitor wine production.

\section{Method}

\subsection{Samples}

Two typologies of wine, namely "Su Masu, Isola dei Nuraghi" from the red grape cultivar Cannonau, and "Semelia" from Vermentino, a white cultivar, were studied; both wines have IGT (Indicazione Geografica Tipica) designations. Samples, coming from 2012 vintage, were kindly donated by the winery of "Azienda Agraria Duca degli Abruzzi" where all the stages, from plant-growing in the vineyard to bottling, were carried out. Grapes were pressed within 24 hours of hand harvesting. The maceration step for Cannonau was carried out in open wooden vat, and for Vermentino directly in the fermentation vessels (stainless steel tanks) with 12 hours contact with skin. Three samples for 4 different vinification times were collected for each grape cultivar, for a total of 24 samples thereafter called: V12, V18, V31 and V66 for Vermentino, C5, C8, C15, C59 for Cannonau, numbers represent the winemaking days starting from harvesting. The sampling procedure ended before fining, filtration and final bottling. Both wines are intended to be drunk young and at the end of winemaking they were not transferred in the wooden barrels, where usually the aging is performed. Vermentino wine "Semelia" is from monovarietal grape, while to the Cannonau "Su Masu, Isola dei Nuraghi", in the final stages of fermentation $\left(16^{\text {th }}\right.$ day), a $10 \% \mathrm{v} / \mathrm{v}$ of Cabernet Sauvignon ( 25 days old, also collected for this study) was added. Cabernet Sauvignon, an international red grape variety, was cultivated in the same vineyard as Cannonau and Vermentino. 


\subsection{Separative Technique}

Bond Elute SPE cartridge C18, containing $500 \mathrm{mg}$ of sorbent and $6 \mathrm{ml}$ of total volume, were purchased from Varian. Methanol (99.8\% Sigma Aldrich), hydrochloridric acid (37\% Sigma) and distilled water were used a solvents. The extraction was performed in a SPE Vacuum device (Supelco) by means of a vacuum pump (15-20 mbar). Following literature indications (Briviba et al., 2002; Edelmann et al., 2001) each sample was dealcoholized and the $\mathrm{pH}$ adjusted to 7 , then centrifuged at $4000 \mathrm{~g}$ for $15 \mathrm{~min}$. The cartridges were preconditioned with $4 \mathrm{~mL}$ of methanol followed by $2 \mathrm{~mL}$ of distilled water. An aliquot of the wine samples $(6$ $\mathrm{mL}$ ) was passed through the cartridges. While the hydrophobic components consisting in the polyphenol fraction of wine were adsorbed in the $\mathrm{C} 18$ column, the polar components were washed with $10 \mathrm{~mL}$ of distilled water. To stabilize the adsorbed molecules, $2 \mathrm{~mL}$ of $\mathrm{HCl} 0.01 \mathrm{M}$ was added to the cartridge (Qin et al., 2010). Finally the hydrophobic components of wine were eluted with $3 \mathrm{~mL}$ of methanol. Measurement of the $\mathrm{pH}$ were carried out for all samples before and after SPE extraction: Vermentino showed $\mathrm{pH}$ averaged values of 3.4 and 2, while Cannonau samples showed values of 3.7 and 1.8, before and after extraction, respectively. The methanolic extracts were analyzed by UV-Vis spectroscopy.

\section{$2.3 \mathrm{UV}$-Visible Spectroscopy}

Spectra of samples were obtained with a Cary50 Probe UV-Visible spectrophotometer, using a 1-cm-thick quartz cell. The spectrophotometer was equipped with a deuterium discharge lamp for UV measurements and a tungsten-halogen lamp for visible, during scanning lamps automatically swap at $370 \mathrm{~nm}$. The measurements were made between 240 and $650 \mathrm{~nm}$, in steps of $1 \mathrm{~nm}$. Repeatability (for absorption value and wavelength shift) was corroborated acquiring the spectrum three times for each sample. According to the scan step, the error on the wavelength shift was $\pm 1 \mathrm{~nm}$. We took special care to define the same baseline (zero value) for all the absorption spectra. All spectra were recorded using methanol as blank. Methanolic extracts were diluted such that the absorption fitted the linear range of the instrument. Experiments were carried out in triplicates. For the MVA, the wavelength range 240 to $650 \mathrm{~nm}$ was selected, the absorption at $370 \mathrm{~nm}$, where the UV and visible lamps swap, was excluded. Spectral data were collected in absorption, their first and second derivatives were also calculated (see Supporting Data). The $\mathbf{X}$ matrix, composed by the whole sample set ( 24 observations) and 409 spectral data was then constructed, ready for MVA.

\subsection{Multivariate Statistical Data Analysis}

MVA was performed by SIMCA-P version 13.0 software package (Umetrics, Umeå, Sweden). Principal component analysis (PCA) and orthogonal projections to latent structures (OPLS) were carried out. Prior to analysis, the data matrix was mean centered column-wise, implying that the average spectrum is subtracted from each of the individual spectrum and unit variance scaled, here each variable is divided by its standard deviation. PCA is an unsupervised explorative technique and, as such, it requires no information about class membership and just looks for inherent variation in the dataset. PCA transforms the variables in a data matrix $\mathbf{X}$ into a smaller number of new latent variables called principal components (PCs). These new variables are linear combinations of the original variables but highlight the variance within the dataset and remove redundancies. The PCs are uncorrelated with each other and are calculated in order of decreasing contribution to the total variance of the original dataset. The dimensionality reduction of the data is obtained excluding the PCs containing less information. Observations (i.e. samples) are assigned scores according to the variation along individual PCs. The explanation of what each PC represents in relation to the original variables, may then be assessed using the loadings. These are a set of weights associated to each of the original variable. Results can be visualized in the score plot where samples are projected and in the corresponding loading plot where variables are reported. When displayed graphically, samples with similar characteristic cluster together and separate out from other groups with differing scores. PLS regression is a multivariate latent-variable method used to find the fundamental relations between 2 data matrices ( $\mathbf{X}$, here the spectral data and $\mathbf{Y}$ the continuous response "days") combining the features of PCA and multiple regression. A PLS model looks for the multidimensional direction in the $\mathbf{X}$ space that explains the maximum multidimensional variance direction in the $\mathbf{Y}$ space. OPLS (orthogonal PLS) is a modification of partial least square regression (PLS) which separates the systematic variation in $\mathbf{X}$ into two parts, one that is linearly related to $\mathbf{Y}$ and one that is orthogonal (irrelevant) to $\mathbf{Y}$. In this work, OPLS technique was used to construct models correlating UV-Vis spectral data with winemaking time. Model performances were evaluated in terms of: amount of explained variation in $\mathbf{X}\left(\mathrm{R}^{2} \mathrm{Xcum}\right)$, amount of variance in $\mathbf{Y}\left(\mathrm{R}^{2} \mathrm{Ycum}\right)$, and amount of $\mathbf{Y}$ cross-validated variance $\left(\mathrm{Q}^{2} \mathrm{cum}\right)$, root mean square error of estimation (RMSEE) and root mean square error in cross validation (RMSEcv). RMSEE and RMSEcv are the standard deviation for the differences between measured and estimated values for samples within the calibration and the cross validation, respectively. Results were visualized as predicted $v s$. observed plot and variable regression coefficient values plot. The former 
represents the relationship between the measured response data and the data predicted by the model. The regression coefficient plot for the variables shows the extent each variable contributed to Y. More details on the MVA methods herein applied, including the standard cross-validation procedures adopted in PCA and OPLS are reported in literature (Eriksson et al., 2013).

\section{Results}

In this work, two typologies of wine were studied, they are produced from Vermentino, a white cultivar, and from Cannonau, a red one. Samples were collected at different vinification times from stainless steel tanks, before fining, filtration and bottling. Moreover, a sample of Cabernet Sauvignon was analyzed since, at the $16^{\text {th }}$ of vinification, Cannonau was blended with a $10 \% \mathrm{v} / \mathrm{v}$ of Cabernet. All samples were subjected to SPE to isolate their polyphenolic contents and analyzed by UV-Vis spectroscopy. Figure 1 shows the UV-Vis spectra in absorbance of the methanolic extracts of Vermentino (A), and of Cannonau and Cabernet Sauvignon (B) at the different times of vinification.
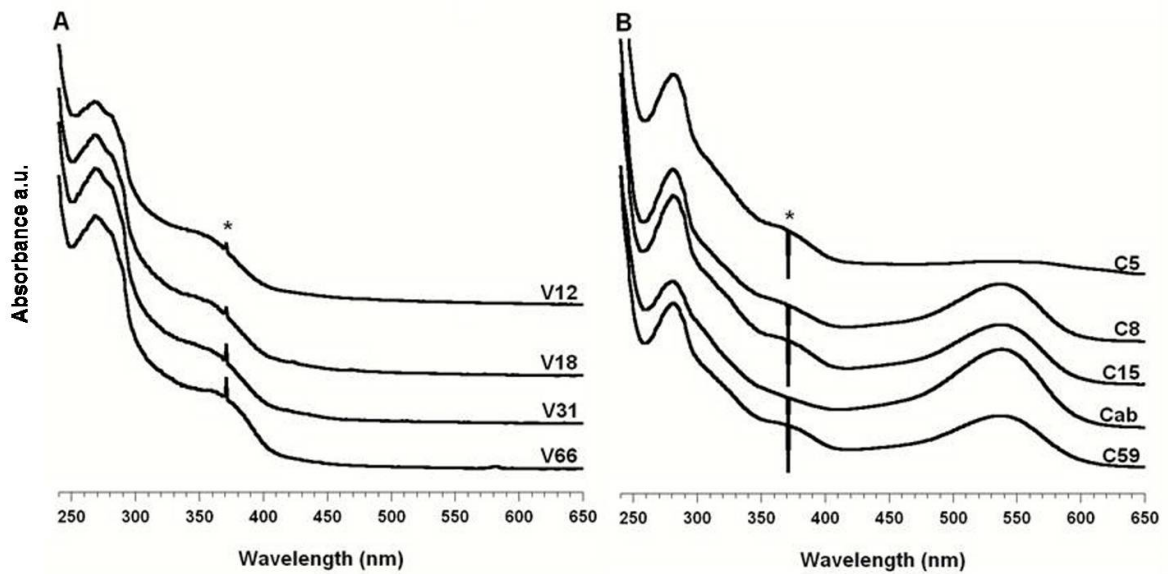

Figure 1. UV-Vis absorption spectra of the SPE polyphenolic extracts of Vermentino (A) and Cannonau (B) wines taken at different times during vinification. See Tables 1 for sample maxima assignments. Spectrum of Cabernet $(\mathrm{Cab})$ is also reported $(\mathrm{B})$. Asterisk indicates lamps swapping

The Vermentino spectra were quite similar showing intense overlapped bands at 268 and 281, and a broad one at $355 \mathrm{~nm}$. This latter, in the sample collected at 66 days (V66), exhibited a slight bathochromic shift centered at around $380 \mathrm{~nm}$. The spectra of Cannonau extracts, reported in Figure 1B, showed an intense band at $280 \mathrm{~nm}$, and two broad bands at 380 and $536 \mathrm{~nm}$. The spectrum of Cabernet extract $(\mathrm{Cab})$, reported in Figure 1B, collected at the $25^{\text {th }}$ day, immediately before addition to Cannonau, showed the same-spectral profile of Cannonau, with the broad band centered at $538 \mathrm{~nm}$. During winemaking, the predominant modification observable in the UV-Vis spectra of Cannonau regarded the increase, from the $5^{\text {th }}$ to the $8^{\text {th }}$ day, of the band at $536 \mathrm{~nm}$. In the spectrum of C59, where Cannonau has been already blended with Cabernet, a slight bathochromic shift with respect to sample C15, of the maximum at $536 \mathrm{~nm}$ to $545 \mathrm{~nm}$ and a skewness of this band, were observed. Band assignments, based on literature (Tuberoso et al., 2013; Castillo-Muñoz, Gomez-Alonzo, Garcia-Romero, \& Hermosin-Gutierrez, 2007; Hang \& Wrolstad, 1990), are reported in Table 1. 
Table 1. Absorption maxima (nm) of UV-Vis bands observed in wine SPE extracts. Assignments are based on literature reports (Tuberoso et al., 2013; Castillo-Muñoz, Gomez-Alonzo, Garcia-Romero, \& Hermosin-Gutierrez, 2007; Hang \& Wrolstad, 1990)

\begin{tabular}{|c|c|c|c|}
\hline \multirow{2}{*}{ Spectral region assignments } & \multicolumn{3}{|c|}{ Samples } \\
\hline & Vermentino & Cannonau & Cabernet \\
\hline \multirow[t]{2}{*}{$\begin{array}{l}\mathrm{HBA}^{\mathrm{a}} \text {, stilbenes, flavan-3-ols, (UV absorbing } \\
\text { fraction of anthocyanins) }\end{array}$} & 268 & & \\
\hline & 281 & 281 & 281 \\
\hline \multirow{3}{*}{ Flavonols } & $355^{\mathrm{b}}$ & & \\
\hline & & 371 & 371 \\
\hline & & & 538 \\
\hline Anthocyanins & & $536^{\mathrm{c}}$ & \\
\hline
\end{tabular}

${ }^{a}$ hydroxybenzoates; ${ }^{\mathrm{b}}$ in sample V66 this maximum exhibits a bathochromic shift to $370 \mathrm{~nm}$; ${ }^{\mathrm{c}}$ in sample C59 this maximum exhibits a bathochromic shift to $540 \mathrm{~nm}$.

Additional information regarding the evolution of polyphenolic extracts during winemaking was extracted from the MVA of the UV-Vis spectral data. Normalized absorption values of the region between 240 and $650 \mathrm{~nm}$ (1 $\mathrm{nm}$ step) of the UV-Vis spectra were used. For overviewing sample patterns in regard to winemaking time and grape typology and for screening of outliers, a PCA of the spectral data of the 24 samples of Vermentino and Cannonau wines collected at different times of vinification, was performed. To note, PCA of spectral data in first and second derivatives were also performed, data in absorption were preferred over these because resulted in higher quality of the models, in terms of: a) easiness of interpretability of the loading plot, b) more defined clustering on the basis of evolution time, c) greater explained variance (See Supporting Data Figure S1, S2 and S3).
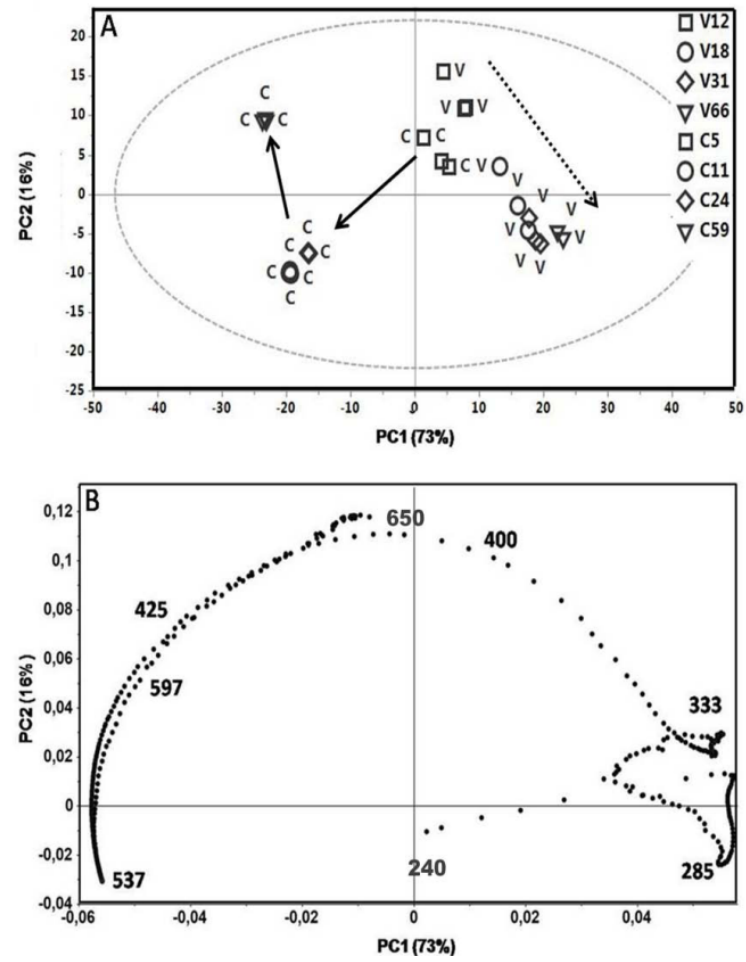

Figure 2. PCA of the UV-Vis spectral data of the SPE polyphenolic extracts of Vermentino and Cannonau samples taken at different times of vinification. In the PC1 vs. PC2 score plot (A), arrows represent time related trajectories. In the corresponding loadings plot (B), the most important absorption wavelengths are reported.

Explained variance (\%) is reported in brackets 
In the PCA (data were mean centered and unit variance scaled column wise) almost all information contained in the spectra were unrevealed by the first 2 PCs that explained $89 \%$ of the total variance, PC1 contributing for the $73 \%$, and PC2 to $16 \%$. Figure 2A shows the plot of samples projected in the bi-dimensional space spanned by the first 2 PCs, here, no one sample fell outside the $95 \%$ (Hotelling T2) confidence ellipse, indicating the absence of potential outliers. Separation of the samples due to grape variety is clearly visible along PC1, while the second dimension is dominated by winemaking times. In particular, Cannonau samples form three well defined clusters, while Vermentino samples are more scattered. The role of the variables in the projection of samples in the space spanned by the first 2 components can be assessed by the analysis of the corresponding loading plot showed in Figure 2B, where the most important UV-Vis wavelengths, influencing sample grouping, are reported. The plot shows interesting features: the right hand (positive PC1) of the plot, where Vermentino samples are projected together with $\mathrm{C} 5$ samples, is characterized by absorptions in the UV wavelength range (around 285 and $330 \mathrm{~nm}$ ), while the negative part of $\mathrm{PC1}$, corresponding to Cannonau clustering, by the wavelengths in the visible range. It is interesting to note that the band at $536 \mathrm{~nm}$ lies in the same region of samples C11 and C24, while sample C59 is characterized by the wavelengths in the regions 424-428 and 596-600 nm, that can be interpreted as an enlargement of the band at $536 \mathrm{~nm}$. Subsequently, a PCA for each wine grape variety was carried out (spectral data were mean centered column wise). The PC1 vs. PC2 score plots for Vermentino and Cannonau are reported in Figure 3A and 3B, respectively.
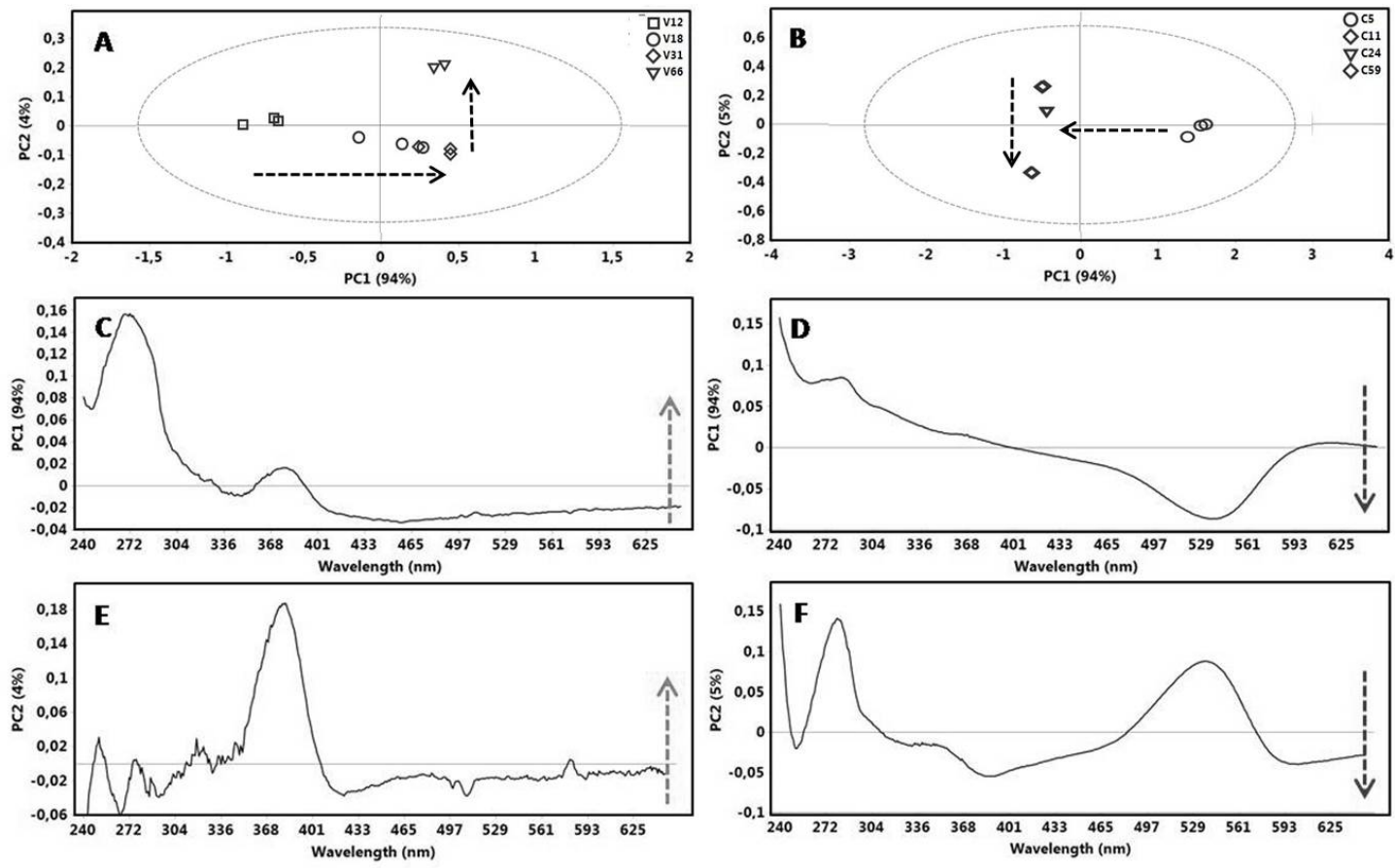

Figure 3. PCA of the UV-Vis spectral data of the SPE polyphenolic extracts of Vermentino and Cannonau samples sampled at different times of vinification. (A) Vermentino PC1 vs. PC2 score plot; (B) Cannonau PC1 vs.

PC2 score plot; loading vector plotted against wavelength for: C) Vermentino PC1; D) Cannonau PC1; E)

Vermentino PC2; F) Cannonau PC2. Arrows, arbitrarily drawn, represent time related trajectories. Explained variance $(\%)$ is reported in brackets

The respective loading vectors along $\mathrm{PC} 1$ and $\mathrm{PC} 2$ were reported against wavelengths, so that they maintain the features of the UV-Vis spectra, and are shown in separate plots (Figures $3 \mathrm{C}$ and $3 \mathrm{E}$ for Vermentino, Figures 3D and $3 \mathrm{~F}$ for Cannonau). In the score plot of Vermentino (Figure 3A), along PC1 a trajectory (from the first sampling (V12) to the third one (V31)) of time process can be drawn; last sampling (V66) is separated along PC2. The analysis of the loading plot along PC1 for this model (Figure 3C) indicates that going from 12 to 31 days there is mainly an increase of the adsorption bands at approximately 280 and $380 \mathrm{~nm}$. The analysis of the loading plot along PC2 (Figure 3E) indicates the band at around $380 \mathrm{~nm}$ as the most important in the last stage of vinification of Vermentino (from 31 to 66 days). The PCA score plot for Cannonau (Figure 3B) shows four well defined clusters: the first sampling (C5) is separated from the others along PC1, while C11, C24 and C59 
samples are displaced along PC2. Considering that PC1 explains most of the variance (94\%) main transformations took place going from day 5 to 11. Analysis of the loading plot along PC1 (Figure 3D) indicated that the band approximately at $536 \mathrm{~nm}$ was the most important exhibiting a marked increase, a slight decrease of the band at $282 \mathrm{~nm}$ is also observable. The other samples (from 11 to 59 days) are separated along PC2 that explains a much smaller variance (5\%). The study of the PC2 loadings (Figure 3F) indicated that the bands around 280, 350 and $536 \mathrm{~nm}$ are mainly involved in these stages of winemaking, decreasing during time. On the contrary, the spectral region around $387 \mathrm{~nm}$ goes in the same direction of time, i.e. increases. These overall results indicate that PCA of the UV-Vis spectral data of the phenolic extracts of wine is a valid tool to study the evolution of these molecular components during winemaking. In order to test the ability of this combined approach to correlate the time of vinification for Cannonau and Vermentino with their phenolic extract evolution, OPLS regression analysis of the UV-Vis spectral data was carried out (See Supporting Data for deeper insights on the application of this PLS tool Figure S4 and S5). Results of the optimized OPLS regression models for Vermentino and Cannonau are shown as predicted $v s$. observed plots in the Figure $4 \mathrm{~A}$ and B, respectively.
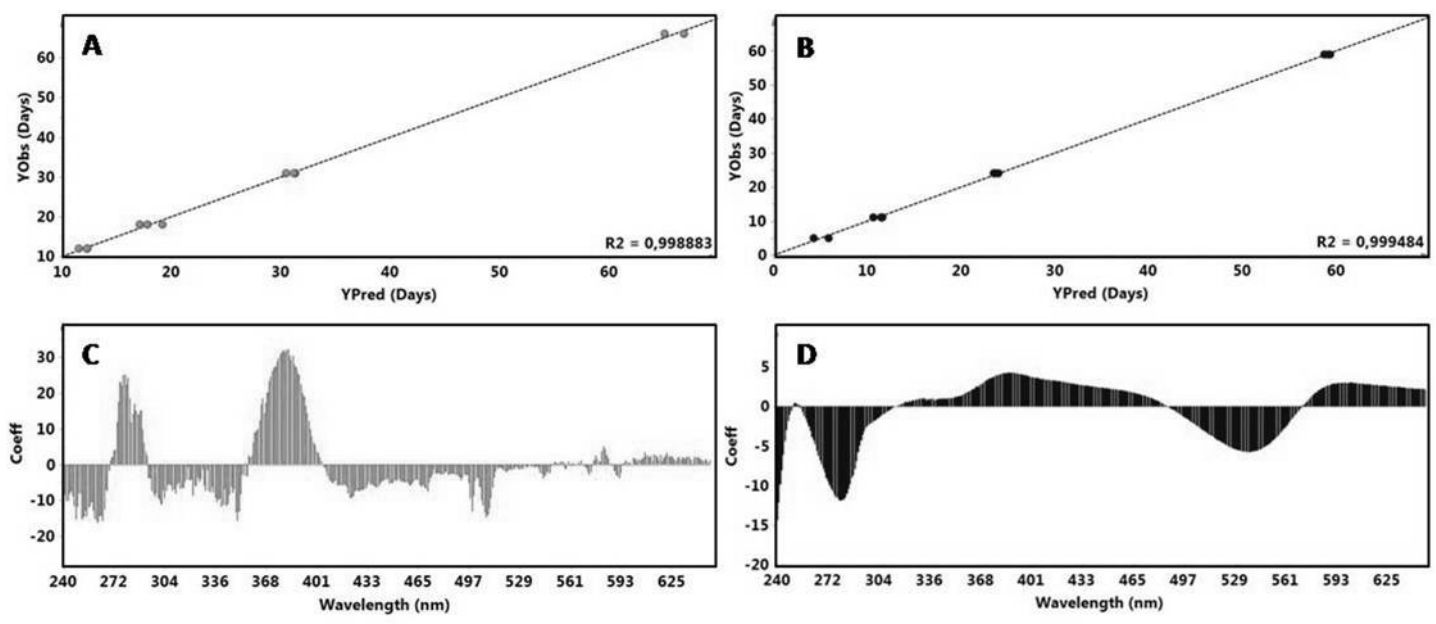

Figure 4. OPLS regression models of the UV-Vis spectral data of the SPE polyphenolic extracts during time. Predicted $v s$. observed plots and corresponding regression coefficient values plotted against wavelengths, for Vermentino (A and $\mathrm{C}$ ) and Cannonau (B and D), respectively. The results are reported in Table 2

Table 2. Results of the OPLS regression models for UV-Vis spectral data of Vermentino and Cannonau polyphenolic extracts, during winemaking time

\begin{tabular}{ccccccc}
\hline Wine type & $\mathrm{N}^{\mathrm{a}}$ & $\mathrm{R}^{2} \mathrm{X}$ & $\mathrm{R}^{2} \mathrm{Y}$ (cum) & $\mathrm{Q}^{2}$ (cum) & RMSEE & RMSEcv \\
\hline Vermentino & $1+3$ & 0.996 (cum) & 0.999 & 0.993 & 0.861 & 1.562 \\
& $\mathrm{P}^{\mathrm{b}}=1$ & 0.415 & & & & \\
& $\mathrm{O}^{\mathrm{c}}=3$ & 0.580 & & & & \\
Cannonau & $1+1$ & 0.987 (cum) & 0.999 & 0.999 & 0.558 & 0.759 \\
& $\mathrm{P}=1$ & 0.328 & & & & \\
& $\mathrm{O}=1$ & 0.660 & & & & \\
\end{tabular}

${ }^{\mathrm{a}}$ number of components; ${ }^{\mathrm{b}}$ predictive, ${ }^{\mathrm{c}}$ orthogonal.

Satisfactory calibration models, validated in cross-validation, were achieved for both wines. Both models show a strong correlation between UV-Vis spectra and time. Results are also depicted as variable coefficient values plots in Figure 4C and D for Vermentino and Cannonau, respectively. These coefficients express how strongly $\mathbf{Y}$ (day) is correlated to the systematic part of each of the $\mathrm{X}$-variables. From the visual analysis of Figure $4 \mathrm{C}$ it can be stated that the spectral regions mainly involved in the evolution of Vermentino, according to the magnitude of 
their coefficient values, are around 280 and $380 \mathrm{~nm}$, which increased in intensity during winemaking. For Cannonau, Figure 4D, more classes of molecules are involved, in particular absorptions at approximately 280 and $536 \mathrm{~nm}$ are inversely correlated with time, while the band around $380 \mathrm{~nm}$ and the bathochromic enlargement of the band centered at $536 \mathrm{~nm}$ are positively correlated.

\section{Discussion}

PCA and OPLS highlighted that consistent modifications, correlated with time, occurred in the UV-Vis spectra of wine polyphenolic fractions. As above reported, the UV-Vis spectra of the polyphenolic extracts from the white wine presented intense overlapped bands at 268 and 281, due to HBA, stilbenes and flavan-3-ols, and at $355 \mathrm{~nm}$, assigned to flavonols in their glycosidic form (Mozetič, Tomazic, Skvarc, \& Trebse, 2006). In the last stage of vinification (sample V66), the band at $355 \mathrm{~nm}$ underwent a bathochromic shift to 370-380 nm. Flavonols are yellow pigments that in grapes are mainly located in the skin in their glycosylated form. In general, white wines do not contain flavonols, because the vinification is performed without contact with the skin. Indeed, they are characterized by non-flavonoid compounds, with absorbance in the UV spectral region (Mozetič et al., 2006). The presence in Vermentino of a broad band centered at around $350 \mathrm{~nm}$ (Figure 1A), attributed to flavonols (mainly Kaempferol- and quercetin-type flavonols) depends on the maceration process where the skin of the berries, rich in flavonols, has been also used (see the 2.1 section), in accordance with the Sardinian winemaking tradition (Sanna et al., 2008; Castillo-Muñoz et al., 2007). Furthermore, the slight bathochromic shift of the flavonol band to $380 \mathrm{~nm}$, previously described for sample V66, can be ascribed to the tendency, over time, of glycosylated flavonols to hydrolyze, thus changing the UV-Vis maxima (Castillo-Muñoz et al., 2007). PCA indicated that in the first weeks of vinification HBA, stilbenes and flavan-3-ols (band at $280 \mathrm{~nm}$ ) increase significantly, together with flavonols. In the last week the predominant effect is the hydrolysis of flavonols. As described in the OPLS regression, this phenomenon, i.e. the increase of the band at $380 \mathrm{~nm}$, is the most correlated to vinification time, probably contributing to the yellowish colour of the white wine. This confirm previous observation regarding the evolution of flavonols undergoing hydrolysis in the last stage of vinification (Castillo-Muñoz et al., 2007). Polyphenol extract spectra of the red wines (Cannonau and Cabernet) presented a band at $281 \mathrm{~nm}$ attributed to HBA, stilbenes and flavan-3-ols and to the UV absorbing part of the anthocyanin structures and a band at $371 \mathrm{~nm}$, characteristic of flavonols (Hang \& Wrolstad, 1990). As stated before for Vermentino, the absorbance at around $370-380 \mathrm{~nm}$ is ascribable to hydrolyzed flavonols (Castillo-Muñoz et al., 2007). Opposite to that observed for Vermentino, in Cannonau the band at $370-380 \mathrm{~nm}$ was present since the first days of vinification; this time related difference among the white and red wines can be due either to the fact that in the 2 wine typologies different classes of flavonols, having different reaction rates, exist or that hydrolysis of flavonols was faster in Cannonau with respect to Vermentino (Castillo-Muñoz et al., 2007). However, from 11 to 59 days, as described by the PC2 loading plot (Figure 4D), a decrease of the absorbance at $350 \mathrm{~nm}$ and an increase of that at $380 \mathrm{~nm}$ was observed. As reported in the OPLS analysis, increase of the absorbance at 380 , and at $280 \mathrm{~nm}$ are the factors most correlated with time. In the Cannonau spectra was also present a band at 536 $\mathrm{nm}$, characteristic of red wines, ascribed to the anthocyanins. Anthocyanins are the most abundant flavonoid constituents of fruits and vegetables. The conjugated bonds in their structures, which absorb light at about $530-540 \mathrm{~nm}$, are the basis for the red, blue and purple colours of fruits, vegetables and their products (Patras, Brunton, ODonnel, \& Tiwari, 2010). The anthocyanins in grape are mainly glucosides of five anthocyanins: malvinidin, delphinidin, peonidin, cyanidin, and petunidin, that occur as 3-o-glucosides, 3-o-acetylglucosides, and 3-o.p.coumaroylglucosides (Mazza \& Francis, 1995). From day 5 to 11, the UV-Vis spectra and PC1 loading plot clearly indicated that the most evident variation in the first week of vinification of Cannonau is ascribable to the increase of the anthocyanin pool, thus indicating extraction of these components from grape skin into wine (Cozzolino, et al., 2004). From the analysis of the PC2 loading plot it can be observed, from day 11 to the last stages of vinification (C59), a decrease of these polyphenols, together with a bathochromic shift of their band. It is worth to note that the decrease of the intensity of the band at $536 \mathrm{~nm}$, is accompanied by a decrease of that at $280 \mathrm{~nm}$ attributed also to the UV absorbing fraction of anthocyanin skeleton. The overall trend observed for the anthocyanin band during vinification of Cannonau is in agreement with previous works reporting that, during vinification, the concentration of monomeric anthocyanins $(500-540 \mathrm{~nm})$, after reaching a maximum level within few days of fermentation (Cozzolino et al., 2006), decreases with the wine still maintaining an essential red color, this latter in agreement with our observed bathochromic shift of the band at $536 \mathrm{~nm}$ (Mazza \& Francis, 1995; Gil-Muñoz, Gomez-Plaza, Martinez, \& Lopez-Roca, 1999). Different explanations have been given for such a marked decrease during vinification, maturation and aging: some of the extracted anthocyanins are adsorbed by yeast cell walls, precipitated with tartaric salts, and reduced by filtration and fining; co-pigmentation effects can also be involved, these normally result in increased absorption intensity (hyperchromism) and a positive shift in the visible wavelength (bathochromism) (Castaneda-Ovando, De Lourdes Paez-Hernandez, Rodriguez, \& 
Galan-Vidal, 2009; Asen, Stewar, \& Norris, 1972). Furthermore, it has been reported that as wine ages, the monomeric anthocyanins react with tannins to form more stable molecules, known as pigmented polymers, that are responsible for the colour for the mature red wine (Harbertson, Picciotto, \& Adams, 2003; Sacchi, Bisson, \& Adams, 2005). In our samples also the blending with $10 \%$ of Cabernet Sauvignon as to be taken into consideration. Blending, in the Italian oenological industry, is a common and standard practice used to naturally increase the colour, the taste, alcohol content, body or aroma of red wines, with the final aim of enhancing the product quality and improve the sensorial properties. Although oenologists have learned through years of work which grape varieties render the best blends, there is very little scientific information supporting this empiric knowledge (Ferrari, Foca, Vignali, Tassi, \& Ulrici 2011; Ferrier \& Block, 2001).

This untargeted approach, that combined UV-Vis spectroscopy and MVA, made it possible to study the whole polyphenolic pool at once, and qualitatively monitor the evolution of these compounds during red and white wine fermentation.

\section{Acknowledgements}

We wish to thanks Prof. Marco Seu for helpful discussions on winemaking methodologies. Gratefully acknowledges Sardinia Regional Government for the financial support (P.O.R. Sardegna F.S.E. Operational Programme of the Autonomous Region of Sardinia, European Social Found 2007-2013 - Axis IV Human Resources, Objective 1.3, Line of Activity 1.3.1 "Avviso di chiamata per il finanziamento di Assegni di ricerca").

\section{References}

Anouar, E. H., Gierschner, J., Duroux, J. L., \& Trouillas, P. (2012). UV/Visible spectra of natural polyphenols: A time-dependent density functional theory study. Food Chemistry, 131, 179-189. http://dx.doi.org/10.1016/j.foodchem.2011.08.034

Asen, S., Stewart, R. N., \& Norris, K. H. (1972). Co-pigmentation of anthocyanins in plant tissues and its effect on color. Phytochemistry, 11, 1139-1144. http://dx.doi.org/10.1016/S0031-9422(00)88467-8

Azcarate, S. M., Cantarelli, M. A., Pellerano, R. G., Markevsky, E. J., \& Camiña, J. M. (2013). Classification of argentinean sauvignon blanc wines by UV spectroscopy and chemometric methods. Food Chemistry, 78, 432-436.

Briviba, K., Pan, L., \& Rechkemmer, G. (2002). Nutrition and cancer red wine polyphenols inhibit the growth of colon carcinoma cells and modulate the activation pattern of mitogen-activated protein kinases. Journal of Nutrition, 132, 2814-2818.

Lubbers, S., \& Volley, A. (1997). Flavor-matrix interactions in wine. $1^{\text {st }}$ International Colloquium Burgundy-California-Oregon, Dijon, France.

Castaneda-Ovando, A., de Lourdes Pacheco-Hernandez, M., Paez-Hernandez, M. E., Rodriguez, J. A., \& Galán-Vidal, C. A. (2009). Chemical studies of anthocyanins: A review. Food Chemistry, 113, 859-871. http://dx.doi.org/10.1016/j.foodchem.2008.09.001

Castillo-Muñoz, N., Gómez-Alonso, S., García-Romero, E., \& Hermosín-Gutiérrez, I. (2007). Flavonol profiles of Vitis vinifera red grapes and their single-cultivar wines. Journal of Agriculture in Food Chemistry, 55, 992-1002. http://dx.doi.org/10.1021/jf062800k

Cheynier, V., Moutounet, M., \& Sanri-Manchado, P. (2000). Los compuestos fenólicos. In C. Flancy (Ed.), Enología: Fundamentos científicos y tecnológicos (pp. 114-136). AMV Ediciones, Madrid, Spain.

Cheynier, V., \& Ricardo Da Silva, J. M. (1991). Oxidation of grape procyanidins in model solutions containing trans-caffeoyltartaric acid and polyphenol oxidase. Journal of Agricultural and Food Chemistry, 39, 1047-1049. http://dx.doi.org/10.1021/jf00006a008

Corder, R., Mullen, W., Khan, N. Q., Marks, S. C., Wood, E. G., Carrier, M. J., \& Crozier, A. (2006). Oenology: red wine procyanidins and vascular health. Nature, 444, 566. http://dx.doi.org/10.1038/444566a

Cozzolino, D., Kwiatkowski, M. J., Parker, M., Cynkar, W. U., Dambergs, R. G., Gishen, M., \& Herderich, M. J. (2004). Prediction of phenolic compounds in red wine fermentations by visible and near infrared spectroscopy. Analytica Chimica Acta, 513(1), 73-80. http://dx.doi.org/10.1016/j.aca.2003.08.066

Cozzolino, D., Parker, M., Dambergs, R. G., Herderich, M., \& Gishen, M. (2006). Chemometrics and Visible-Near Infrared spectroscopic monitoring of red wine fermentation in a pilot scale. Biotechnology and bioengineering, 95(6), 1101-1107. http://dx.doi.org/10.1002/bit.21067 
Cozzolino, D., Cynkar, W. U., Shah, N., Dambergs, R. G., \& Smith, P. A. (2009). A brief introduction to multivariate methods in grape and wine analysis. International Journal of Wine Research, 1(1), 123-130. http://dx.doi.org/10.2147/IJWR.S4585

Edelmann, A., Diewok, J., Schuster, K. C., \& Lendl, B. (2001). Rapid method for the discrimination of red wine cultivars based on mid-infrared spectroscopy of phenolic wine extracts. Journal of Agricultural in Food Chemistry, 49, 1139-1145. http://dx.doi.org/10.1021/jf001196p

Eriksson, L., Johansson, E., Kettaneh-Wold, N., Trygg, J., Wikström, C., \& Wold, S. (2013). Multi- and Megavariate Data Analysis. Third edition; Umetrics Academy, Sweden.

Ferrari, E., Foca, G., Vignali, M., Tassi, L., \& Ulrici, A. (2011). Adulteration of the anthocyanin content of red wines: Perspectives for authentication by Fourier Transform-Near InfraRed and ${ }^{1} \mathrm{H}$ NMR spectroscopies. Analytica Chimica Acta, 701, 139-151. http://dx.doi.org/10.1016/j.aca.2011.05.053

Ferrier, J. G., \& Block, D. E. (2001). Neural-network-assisted optimization of wine blending based on sensory analysis. Analytica Chimica Acta, 52, 386-395.

Fontoin, H., Saucier, C., Teissedre, P. L., \& Glories, Y. (2008). Effect of pH, ethanol and acidity on astringency and bitterness of grape seed tannin oligomers in model wine solution. Food Quality and Preference, 19, 286-291. http://dx.doi.org/10.1016/j.foodqual.2007.08.004

Gao, L., Girard, B., Mazza, G., \& Reynolds, A. G. (1997). Changes in anthocyanins and color characteristics of Pinot Noir wines during different vinification processes. Journal of Agricultural in Food Chemistry, 45, 2003-2008. http://dx.doi.org/10.1021/jf960836e

Garcia-Jares, C. (1993). Research of white and red wine bleanding in the production of the rosè wines by means of the partial least square method. Journal of Science in Food Agriculture, 63, 349-354. http://dx.doi.org/10.1002/jsfa.2740630313

Gil-Muñoz, R., Gómez-Plaza, E., Martínez, A., \& López-Roca, J. M. (1999). Evolution of phenolic compounds during wine fermentation and post-fermentation: influence of grape temperature. Journal of Food Composition and Analysis, 12, 259-272. http://dx.doi.org/10.1006/jfca.1999.0834

Gishen, M., Dambergs, R. G., \& Cozzolino, D. (2005). Grape and wine analysis-enhancing the power of spectroscopy with chemometrics. Australian Journal of Grape and Wine Research, 11(3), $296-305$. http://dx.doi.org/10.1111/j.1755-0238.2005.tb00029.x

Gonzàles-Manzano, S., Duaas, M., Rivas-Gonzalo, J. C., Escribano-Bailón, M. T., \& Santos-Buelga, C. (2009). Studies on the copigmentation between anthocyanins and flavan-3-ols and their influence in the colour expression of red wine. Food Chemistry, 114, 649-656. http://dx.doi.org/10.1016/j.foodchem.2008.10.002

Hong, V., \& Wrolstad, R. E. (1990). Characterization of anthocyanin-containing colorants and fruit juices by HPLC photodiode array detection. Journal of Agriculture in Food Chemistry, 38, 698-708. http://dx.doi.org/10.1021/jf00093a025

Harbertson, J. F., Picciotto, E. A., \& Adams, D. O. (2003). Measuring polymeric pigments in grape berry extracts and wines using a protein precipitation assay combined with bisulfite bleaching. American Journal of Enology Viticulture, 54, 301-306.

Mazza, G., \& Francis, F. J. (1995). Anthocyanins in grapes and grape products. Critical Review in Food Science and Nutrition, 35, 341-371. http://dx.doi.org/10.1080/10408399509527704

Mozetič, B., Tomažič, I., Škvarč, A., \& Trebše, P. (2006). Determination of polyphenols in white grape berries cv. Rebula. Acta Chimica Sloenica, 53, 58-64.

Patras, A., Brunton, N. P., O’Donnell, C., \& Tiwari, B. K. (2010). Effect of thermal processing on anthocyanin stability in foods; mechanisms and kinectics of degradation. Food Science and Technology, 21, 3-11. http://dx.doi.org/10.1016/j.tifs.2009.07.004

Pinelo, M., Laurie, V. F., \& Waterhouse, A. L. (2006). A simple method to separate red wine nonpolymeric and polymeric phenols by solid-phase extraction. Journal of Agricultural in Food Chemistry, 54, 2839-2844. http://dx.doi.org/10.1021/jf052814a

Qin, C., Li, Y., Niu, W., Ding, Y., Zhang, R., \& Shang, X. (2010). Analysis and characterization of anthocyanins in mulberry fruit. Food Science, 2, 117-126. 
Ribéreau-Gayon, R., Glories, Y., Maujean, A., \& Dubourdieu, D. (2006). Phenolic compounds. Handbook of Enology (Vol. 2, pp. 141-204). John Wiley \& sons, Chichester, UK.

Rice-Evans, C. A., Miller, N. J., \& Paganga, G. (1997). Antioxidant properties of phenolics compounds. Trends Plant Science, 2, 152-159. http://dx.doi.org/10.1016/S1360-1385(97)01018-2

Sacchi, K. L., Bisson, L. F., \& Adams, D. O. (2005). A review of the effect of winemaking techniques on phenolic extraction in red wines. American Journal of Enology Viticulture, 56, 197-206.

Sanna, G., Ledda, S., Manca, G., \& Franco, M. A. (2008). Characterization of the content of the antioxidants substances in Sardinia wine. Journal of Commodity Science, Technology and Quality, 47, 5-25.

Sarni-Manchado, P., Cheynier, V., \& Moutounet, M. (1997). Reactions of polyphenoloxidase generated caftaric acid o-quinone with malvidin 3-O-glucoside. Phytochemistry, 45, 1365-1369. http://dx.doi.org/10.1016/S0031-9422(97)00190-8

Saurina, J. (2010). Characterization of wines using compositional profiles and chemometrics. TrAC Trends in Analytical Chemistry, 29(3), 234-245. http://dx.doi.org/10.1016/j.trac.2009.11.008

Tuberoso, C. I., Boban, M., Bifulco, E., Budimir, D., \& Pirisi, F. M. (2013). Antioxidant capacity and vasodilatory properties of Mediterranean food: the case of Cannonau wine, myrtle berries liqueur and strawberry-tree honey. Food Chemistry, 140, 686-691. http://dx.doi.org/10.1016/j.foodchem.2012.09.071

Urbano, M., Luque De Castro, M. D., P'erez, P. M., Garc'ia-Olmo, J., \& G'omez-Nieto, M. A. (2006). Ultraviolet-visible spectroscopy and pattern recognition methods for differentiation and classification of wines. Food Chemistry, 97, 166-175. http://dx.doi.org/10.1016/j.foodchem.2005.05.001

Vidal, S., Francis, L., Guyot, S., Marnet, N., Kwiatkowski, M., Gawel, R., Cheynier, V., \& Waters, E. J. (2003). The mouth-feel properties of grape and apple proanthocyanidins in a wine-like medium. Journal of the Science of Food and Agriculture, 83, 564-573. http://dx.doi.org/10.1002/jsfa.1394

Vidal, S., Francis, L., Noble, A., Kwiatkowski, M., Cheynier, V., \& Waters, E. (2004). Taste and mouth-feel properties of different types of tannin-like polyphenolic compounds and anthocyanins in wine. Analytica Chimica Acta, 513, 57-65. http://dx.doi.org/10.1016/j.aca.2003.10.017

\section{Copyrights}

Copyright for this article is retained by the author(s), with first publication rights granted to the journal.

This is an open-access article distributed under the terms and conditions of the Creative Commons Attribution license (http://creativecommons.org/licenses/by/3.0/). 